\title{
CUIDAR em SAÚDE: lugar da invenção de um novo paradigma científico
}

\section{CARE IN HEALTH: PLACE OF INUENTION OF A NEW SCIENTIFIC PARADIGM \\ CUIDAR EN SALUD: LUGAR DE INUENCIÓN DE UN NUEVO PARADIGMA CIENTÍFICO}

\author{
Nebia M. Almeida de Figueiredo ${ }^{1}$ \\ Iraci dos Santos ${ }^{1}$ \\ Vera Regina Salles Sobral ${ }^{1}$ \\ Osnir Claudiano da Silva. Jr. ${ }^{2}$
}

RESUMO: É um ensaio sobre o Cuidado, centro de atenção da prática e da pesquisa, como lugar de invenção, teste, crítica e reconstrução do saber específico da enfermagem. Saúde e bem-estar, qualidade e "L' état de I' art ", e ainda a experiência do cuidado nos corpos dos clientes e dos enfermeiros estão em discussão.

PALAVRAS-CHAVE: Enfermagem - Cuidado - Ciência.

ABSTRACT: It is an essay about Care, basis of the practice and research, as place of invention, test, criticism and reconstruction of the Nursing specific knowledge. Health and well-being, quality, "L'état de l'art " and, yet, the experience of caring at the patients and Nurses' bodies are discussed.

KEYWORDS: Nursing - Care - Science

RESUMEN: És un ensayo sobre el cuidado, centro de atención de la práctica y de la investigación, como el lugar de invención, test, crítica y reconstrución del saber específico de enfermería. Están en discusión: salud y bienestar, calidad y "L' état de I' art", además de la experiencia del cuidado en los cuerpos de los clientes y de los enfermeros.

PALABRAS CLAVE: Enfermería - Cuidado - Ciencia.

' Enfermeiras. Doutoras em Enfermagem. Professoras da Universidade do Rio de Janeiro(UNI-RIO), Universidade do Estado do Rio de Janeiro (UERJ) e Universidade Federal Fluminense (UFF), respectivamente.

${ }^{2}$ Doutorando da EEAN. Professor da UNI-RIO

R. Bras. Enferm. Brasilia, v. 51, n. 3 p. 447-456, jul./set., 1998 


\section{- O QUE É CUIDAR?}

Abandonando os conceitos, aprendidos e repassados para nossos clientes sobre saúde e cuidado, tentamos encontrar para eles uma inserção num espaço de expressão e sensibilidade, numa abordagem criativa e coletiva, numa ação de solidariedade, liberdade e parceria.

O cuidado nasceu no espaço privado, na familia, sendo a mulher a primeira pessoa a cuidar do filho, do marido, dos parentes, dos vizinhos e a passar essa experiência para as filhas que iam disseminando pelas comunidades 0 conhecimento de cuidar.

Desse modo, o cuidado traz uma marca "genética" - a sensibilidade, a compaixão/compreensão/amor, aconchego, a ajuda tão comum no comportamento das mulheres. Portanto, este cuidado não se conforma no paradigma científico cartesiano/biomédico.

Outra marca, discutida por Sobral e Figueiredo (1996), aliada ao cuidado é a histórica e cultural da enfermagem como profissăo feminina proporcionando, às que dela fizeram o seu espaço de trabalho, uma alternativa particular visando possibilidades além da vida doméstica e familiar.

Deve-se recordar que a enfermagem é uma profissão ainda com diferenças de valores (culturais e éticos) amplamente desiguais. Sempre teve a espantosa incoerência de aproximar mulheres de estilos de vida contrários: irmãs de caridade, a cuidar do corpo do outro para melhor se purificar e aliviar suas almas; prostitutas, a expiar sua culpa cuidando dos moribundos e Florence Nightingale, como mito de origem da enfermagem moderna mundial-mulher culta, bem nascida, econômica e politicamente bem colocada no mundo público e privado. Históricamente o cuidado foi construido e praticado através das mulheres, independentemente de ser um saber cientifico ou do senso comum.

Assim, abre-se um espaço desde o que afirma Santos (1997) - a enfermagem tem uma especificidade de conhecimento porque o seu objeto privilegiado de investigação é o ser humano. Diz a autora que é necessário que as(os) enfermeiras(os) busquem métodos próprios para sedimentar e aperfeiçoar o próprio saber pois a validade científica na enfermagem advém não só do seu pensar e fazer profissional como também da própria busca de caminhos adequados para o estudo do seu objeto de pesquisa.

Horta, (1977) anunciou um conceito aceito pelas brasileiras - "enfermagem é gente que cuida de gente". Esta, talvez, seja uma característica desta profissão dificil de ser teorizada, cientificada. Um ser humano único (que cuida ou é cuidado) colocando o seu arsenal emocional (dúvidas, medo, coragem, prazer, desprazer) e seus conhecimentos técnicos e tecnológicos em favor do outro (com um universo de saberes riquíssimo!') que precisa ser cuidado (Santos, 1997).

Nesta profissão nos parece fundamental reconhecer uma aprimorada proposta de solidariedade humana; algo diferente da caridade inerente ao domínio religioso, qual seja, a solicitude de quem cuida para quem é cuidado; o respeito e a compreensão da fragilidade e complexidade de um ser humano por outro, conforme afirma Santos (1997). 
Curioso é o momento em que o cuidado deixou a esfera do privado e se transformou numa atividade a ser exercida num espaço público, desligada dos aspectos familiares e feita por pessoas estranhas ao sujeito a quem ele se destina. Falamos daquele cuidado oferecido tradicionalmente como fruto de uma acumulação cultural e tecnológica desenvolvida pelas mulheres, apropriado pela ideologia religiosa.

Outro aspecto é a variedade cultural existente no Brasil. De norte a sul, de leste a oeste, uma incrivel mistura de raças e culturas nativas e importadas contribui com saberes para o processo saúde / doença, ou melhor, - bemestar/mal-estar. Recorda-se que o modelo biomédico ocidental, ao longo dos séculos, foi esmagador sobre o vasto arsenal cultural deste processo. Assim, impediu-se, muitas vezes, por bem da ciência (ou "por ordem médica"), ligações entre os indivíduos e suas raizes culturais mais profundas - e soube-se proibir muito bem!

Não se trata aqui de colocar em campos opostos o saber médico (antibiótico) e o saber da benzedeira, (ecológico) mas observar que a busca do simbólico foi o fundamental elemento na relação terapêutica em todas as culturas e parece ter sofrido sérias fraturas no modelo de assistência à saúde (ou a doenças?) em nossos dias. A procura desta relação no que se passou a chamar de "práticas alternativas" remete à pergunta: o que é tradicional e o que é alternativo - 1000 anos de acupuntura ou 50 de antibióticos? A resposta para tal questão deve demonstrar nossa explanação.

A enfermagem tem cabido muitas vezes a posição dificil de preparar um corpo humano para a intervenção de saberes e poderes de outros seres humanos. Assim, despe-se os individuos de suas crenças por mecanismos bastante duvidosos. Aculturamento do cuidado?

Uma nova possibilidade de leitura das influências das questões culturais e subjetivas da produção e reprodução do bem-estar e mal-estar se processa neste final de milênio. Para nós, uma perspectiva transcultural já foi anunciada por Leininger (1985) e nos parece ter repercussões e expressar nosso interesse por temas ligados às outras esferas da dinâmica do funcionamento desta curiosa espécie humana e daqueles que se propõem a dela cuidarem. Acreditamos estar avançando e encontrando uma "brecha" através da imaginação, da utopia, da realidade que, inscrita na subjetividade, envolve sentidos-sexualidadesensibilidade e arte, ao seguirmos a abordagem Sócio-Poética de Gauthier e Santos (1996).

\section{- O QUE É SAÚDE?}

Nosso entendimento sobre saúde nos parece novo e atual: queremos pouco saber se as pessoas têm saúde, queremos mais saber se elas possuem bemestar. Isto encerra uma caracteristica marcante como conceito prático. Entender bem-estar como saúde e mal-estar como desvio de saúde abre novas frentes de estudos e resolução de problemas que envolvem a enfermagem e seus clientes. 
Desse modo, introduzimos novos elementos na noção de causalidade do mal-estar deslocando seu eixo dos agentes patogênicos que desviam a saúde para uma idéia de multicausas. Significa outros fatores como:

a) ecologia - ambiente, condições materiais de vida, relações sociais de gênero - viver, conviver, trocar experiências e subjetividade humana;

b) política - possibilidade de conservar os direitos da pessoa que tem desejos, portanto direitos naturais. O poder regulador da prática em muitos momentos cria ações nocivas que podem ser delimitadoras da liberdade e causadoras de mal-estar envolvendo açöes governamentais, institucionais, familiares;

c) espiritualidade - possibilidade de criar, sonhar, brincar, imaginar liberdade para ser e estar; de acreditar, conhecer e de transcender;

d) economia - as desigualdades sociais, subdesenvolvimento econômico, desemprego e a falta de perspectiva de uma vida melhor aumentam os desvios de saúde e são fatores a indicar que o processo de mal-estar pode ter origem em agentes patológicos, como os microorganismos, mas também nos sons, emoçōes, desconhecido, "não dito", e outros, provenientes do próprio desenvolvimento tecnológico e das relaçőes que mantemos com o mundo, com o outro e conosco.

O bem-estar como saúde impöe-se no compromisso dos profissionais desejosos em evitar que diversos processos e fatores desviem o homem do estado de bem viver. Interrogar com vistas à socializaçäo, o respaldo do poder médico, ainda permanente e delegando este poder para outros grupos, é empreender um novo papel pois no mundo todos são responsáveis pela célula do movimento sanitário, ou seja, o cuidado com: filhos, familia, planeta, terra, instituiçőes, diferentes, doentes, moribundos, ambiente, relaçōes; é, ainda, alertar para a subjetividade humana que move e colore a própria vida. É preciso desinstitucionalizar o hospital como lugar de doença acreditando na assertiva de Clarke .(1989) ao dizer que: o hospital é um lugar para controle e manutenção da saúde, um espaço para discussão de questões envolvendo etnia, política, reflexão; de construção e desconstrução, reconstrução de conhecimentos e de ideologias. Refletir sobre esta assertiva nos faz afirmar: queremos um espaço onde os doentes não sejam segregados para não infectar e amedrontar a sociedade; queremos um lugar onde as pessoas tenham direito ao cuidado e conforto para reversão dos processos de mal-estar em bem-estar.

\section{A QUALIDADE DO CUIDADO}

Estas idéias nasceram e se aplicam á prática de cuidar em saúde há muitos anos $e$ indicam uma inserção para o que entendemos como bem-estar e qualidade de cuidar.

Descrevemos bem-estar e qualidade como "degraus" facilitadores da subida para o estado ótimo, cuja descida poderá ser considerada desvio do tal estado-o 
mal-estar. Subir e descer é uma questão pessoal e pode-se assegurar: nem sempre quem desce estará doente. Podemos descer na escada do bem viver a fim de fazer ajustes, rever posiçס̋es e para repensar bem-estar e mal-estar.

A definição oficial da International Standard Organization (ISO), citada por Tebout (1991:16), diz: "qualidade é um conjunto das propriedades e características de um produto, processo ou serviço que fornece a capacidade de satisfazer as necessidades explicitas e implícitas dos usuários"

No caso da enfermagem, as primeiras noticias que se tem sobre ações de qualidade surgiram através de Florence Nightingale por ocasiäo da guerra na Criméia, quando esta organizou uma unidade para tratar os feridos e adotou técnicas de cuidados inovadoras naquela época.

O tema qualidade, no Brasil, destacou-se na década de 80 e inicio de 90 , principalmente na área industrial e comercial, e, só agora vem sendo pensado com seriedade ou melhor, com vistas ao bem-estar.

Cuidado é, portanto, um produto que ofertamos à clientela. Pensar na sua qualidade envolve fatores condicionantes de satisfação de quem o recebe $\mathrm{e}$ satisfação de quem o oferta. Eis a questão.

Qualidade na enfermagem envolve além de uma prática incluindo desenvolvimento de técnicas, habilidades psico motoras e conhecimento cientifico para ofertar segurança àquele que necessita de cuidados; envolve saber se emocionar, criar, sonhar, intuir, imaginar, pesquisar, cuidar.

Se esta profissão pressupöe arte, ética e ciência tem muito mais a oferecer e está mais para uma ciência sensual do que qualquer outra desenvolvida pelo paradigma de cientificidade dominante.

Nosso projeto para uma teoria-prática de cuidar baseia-se em dimensões envolvendo o próprio corpo que cuida e o que é cuidado, como força e poder indissociável á vida e, portanto, ao bem-estar. Nele os sentidos, intuição, sensualidade, sensibilidade, sexualidade e solidariedade são capazes de criar modos de viver, cuidar, organizar-se, desorganizar-se, reorganizar-se, compreender a complexidade da vida entendida, por Morin (1996), como a incerteza no seio de sistemas ricamente organizados. Está, portanto, ligado a uma certa mistura de ordem e desordem (pobre e estática); reina no nível das grandes populações e no da ordem (pobre, pura, indeterminada) das unidades elementares. Pensar na enfermagem como o lugar do cuidado é pensar em complexidade; é poder trabalhar com o insuficiente e o vago e aceitar a ambigüidade nas relações sujeito/receptor do cuidado, ordem/desordem autohetero organização; exige o reconhecimento de fenômenos como liberdade ou criatividade, inexplicáveis fora do quadro complexo e único que permite a sua aparição.

Este é um lugar de inserção para uma nova abordagem do conhecimento A Sócio-Poética - um novo paradigma científico no qual a pesquisa em enfermagem pode atender a especificidade e a complexidade de sua prática para teorizar e criar concepções adequadas ao que se entende como bemestar. 
Pensemos, também, no nosso modo de ser e no dos clientes levando em consideração a razão de existir, a utopia fundadora das Instituições descrita por Lourau (1996). Como afirma Santos (1997), "devemos estudar nas Instituições questões que afetam os clientes, profissionais, disciplinares e interdisciplinares reconhecendo-os como parceiros para a construção do conhecimento, pois eles não são apenas informantes, são, também, co-responsáveis por tudo aquilo que acontece".

Assim, encontramos uma outra inserção para falar de cuidado e saúde que compreende três momentos: procurando um espaço; escolhendo um método e pensando numa ação, os quais não conceituamos por concordarmos com Deleuze - o conceito aprisiona as idéias, as essências contidas nas ações, nas coisas, nos gestos. "Conceituar é matar a idéia". Tudo fica imensamente simplificado, tudo fica imensamente falsificado.

\section{- PROCURANDO um ESPAÇO de EXPRESSÃo}

Encontrar um espaço para pesquisar diferente do que existe é detonar, segundo o pensamento de Guattari.

Neste momento, destacamos uma experiência profissional como exemplo de bem e mal-estar. A fim de o(a) cuidador(a) sentir na própria pele o que é ser cuidado(a), resolvemos pesquisar um procedimento denominado banho no leito. Durante a pesquisa, as enfermeiras se colocam como clientes e aceitam ser banhadas. O banho no leito, para cliente e cuidador, é uma invasão de intimidade ao mesmo tempo em que é uma ação profissional visando conforto, higiene, prazer, bem-estar.

Esta experiência serviu, naquele momento, para "desencadear" questões ligadas à sexualidade e às nossas próprias dificuldades em tocar/olhar o corpo nu de alguém tão próximo de nós (especialmente, cotidianamente, afetivamente . e profissionalmente).

Quanto à sexualidade, como força de vida, de bem-estar, ela é entendida como a forma de nos colocarmos no mundo enquanto sujeito e interagirmos com ele. São questōes sobre o "não dito" ou envolvendo "falas" para denegar o que deveríamos afirmar. Nossas dificuldades são imputadas ao fato de sermos uma profissão autorizada socialmente a tocar qualquer parte do corpo do outro, inclusive, no espaço público.

São questões históricas, políticas e culturais que perpassam situações de gênero, de raça, de etnia e de linguagem e, assim, descobrimos as dificuldades guardadas em nosso inconsciente e jamais colocadas em discussão.

Acreditamos que os estudos ora desenvolvidos devam criar nas enfermeiras, principalmente naquelas que vivenciaram essa ação de cuidar do corpo-vivoquente, reflexão e interesse sobre esta tecnologia de enfermagem. A pesquisa citada desencadeará reflexões, e estudos sobre as práticas profissionais e as respostas destas no corpo do cliente. Assim, elas assumirão a dignidade de açōes complexas, sensiveis, verdadeiras terapêticas de conforto, proporcionadas pela enfermagem. 
Podemos acrescentar: este é um novo espaço para teorizar cuidar em enfermagem, promover o bem estar. Um lugar onde a encenação acontece e desperta nas pessoas reflexões sobre o objeto representado, pensado, imaginado.

É, sem dúvida, um espaço de construção, desconstrução e reconstrução de saberes, modos de pensar diversos para produzir teoria, internalizar conhecimentos considerando-se o ambiente onde se processa o cuidado como $o$ laboratório de pesquisa. É um lugar onde exercitamos a sensibilidade do corpo para nos comunicar, sonhar, imaginar, criar, concretizar utopias e racionalizar a partir de uma realidade. Nele, o movimento é feito através de ação-reflexãoação, desde os problemas trazidos pelos sujeitos, de suas vivências em casa, no trabalho, na rua. Estes movimentos corporais produzem conhecimentos que envolvem dimensões estética, política, social, ambiental, cultural, ecológica e a subjetividade.

\section{- ESCOLHENDO UM MÉTODO}

Concordamos com Gauthier e Santos (1996) quanto à necessidade de incentivar nas pessoas a expressão do seu saber implicito, num sentido crítico a fim de que elas possam criar, produzir conhecimento. Isto porque a própria civilização, a cultura, no decorrer dos tempos, tem contribuído para a repressão de tudo que nos é natural. Em nossa área de saber percebe-se claramente algumas oposições cultura-natureza, tais como: tecnologia - criatividade; sensualidade - formalismo/profissionalismo; tecnicismo - sensibilidade; privilegiamento da razão - intuição; assexualidade - sexualidade. (na educação tradicional de enfermagem costumava-se dizer às(aos) alunas(os) que "enfermeira(o) não tem sexo", e não se emociona para não perturbar o cliente. Assim, esta profissional devia ser impassivel, neutra, insipida e também, inodora, científica e asséptica. Às vezes até o doente, assim devia ser considerado, principalmente, assexuado. Desse modo é indispensável liberar o imaginário das pessoas a fim de que elas primeiro se conheçam e aceitem os componentes de sua humanidade, a qual não é feita apenas da razão, geralmente, aceita como única para a cientificidade.

Os autores referidos apresentam a Sócio-Poética como uma abordagem no conhecimento do ser humano. Portanto, nada mais apropriado para investigar entre e com as pessoas o que Ihes causa bem e mal-estar e quais cuidados lhes parecem mais confortáveis e agradáveis, ou seja, mais promotores de bemestar.

Um paradigma científico voltado para o desejo de saber, a curiosidade natural das pessoas e não apenas a curiosidade meramente científica, procedente de interesses politicos e econômicos dos pesquisadores, certamente proporciona a construção coletiva de saberes dentro do próprio grupo neles interessados.

Portanto, a Sócio-Poética, ao propiciar um processo de criação/ desestabilização nas pessoas, liberando coisas escondidas, esquecidas e 
recalcadas, atinge suas dimensōes fisica, intelectual e espiritual, impedindo que o conhecimento produzido dentro do grupo esteja ligado apenas às questöes ideológicas e institucionais.

No caso da enfermagem - "a gente que cuida de gente", pesquisar com a Sócio-Poética representa a fidelidade à sua razão de existir, qual seja, fundamentar-se num profundo respeito humano, para lidar com as pessoas. Este é seu compromisso profissional e sua dimensão ética na pesquisa pois é preciso reforçar: sendo seu objeto de estudo - o próprio ser humano - não se faz enfermagem sem construção, desconstrução, reconstrução de saberes para o bem-estar dos seres humanos.

Desse modo, o pesquisador, aderente à Sócio-Poética, deve estar alerta não só para os sentimentos e a razão, as emoçőes e a intuição, sensualidade, sexualidade mas, principalmente, para a solidariedade. Ele deve compartilhar com as pessoas a quem e com quem pesquisa e durante esta, os seus prazeres, medos e angústias. Deve com elas se incentivar para reafirmar forças de vida, respeito, alegria, imaginação e libertação, formando na realização da pesquisa um Grupo-Pesquisador, conforme afirmam Gauthier e Santos (1996). Recordase, ainda, que estes autores vislumbram na Sócio-Poética um educar mutual e uma relação de auto-ajuda entre pesquisadores e seus grupos de pesquisa.

Então, com a Sócio-Poética, acontece, além da criação coletiva de saberes a apropriação destes, haja vista a citada abordagem promover entre os pesquisadores o conhecimento de si próprio, do mundo e dos outros.

A Sócio-Poética, ao produzir uma poesia crítica e viva, transforma o conhecimento desde os próprios participantes da pesquisa. Conhecimento este cuja linguagem pode ser por todos e além do grupo entendida por não ser apenas um produto academicista, exclusivo da cientificidade ou do mero pesquisador.

\section{- PENSANDO numa AÇÃO}

Insistimos no cuidado como uma atividade fim no trabalho da enfermagem e um meio de valorização profissional quando é realizado com arte (Criatividade, estética), ética (respeito, compreensão) e ciência (conhecimento, pesquisa). O cuidado produz o bem-estar, bem viver - o bem maior a que tem direito o homem. Assim, enfermagem tem como cliente todos os seres humanos. Aqui encontramos o método deste novo paradigma cientifico considerando as pessoas que conosco compartilham a aventura do cotidiano saber viver $\mathrm{e}$ conviver (colegas, alunos, clientes) como co-pesquisadoras, com elas formemos - Grupo-Pesquisador criado por Gauthier e Santos (1996). Esta é uma exigência ética, além dos padrões e razões da tradicional cientificidade.

A ação de cuidar se apoia em bases científicas e se utiliza dos materiais citados por Figueiredo (1997): a terra - a ecologia do cuidado e a saúde ambiental; o sopro - a vida e sua origem, as pistas - semiologia para um diagnóstico de enfermagem. 
O saber assim fundamentado encontra-se em pulsões, emoção, desejo e prazer do corpo. A práxis revela o modelar o cuidado no corpo por um outro corpo. Esta é a alquimia do cuidado.

A lógica para as ações de cuidar depende de uma viagem ao passado pensar o presente e projetar formas de sentir e dar o cuidado.

O cuidar exige de nós uma atenção para o estado de bem-estar como esperança de nascer, viver e morrer - esperança de viver para criar espaços (nas instituiçöes) e condições nas quais a natureza exerça sua força para manter o bem-estar ou promover a recuperação do mal-estar.

Nesta invenção de um novo paradigma cientifico incluem-se estratégias para a prática de cuidar e de ensinar a cuidar: a conhecer o sujeito que se encontra no mundo, na família, no social e consigo mesmo, intervir na perspectiva de melhorar seu bem-estar construindo um espaço de comunicação, transformação e produção de saberes e tecnologias, considerando os aspectos econômicos, culturais e político-sociais, encontrar espaço para ensinar crianças, adolescentes e adultos a tornarem-se cidadāos em equilibrio com sua ecologia, entendendo-o como imaginários e reais; procurar espaços, de encantamentos para a reflexão e discussão dos modos de viver, de ser e de estar no mundo, numa perspectiva transcultural e transdisciplinar.

Portanto, neste novo paradigma científico deve-se vislumbrar um horizonte onde o cuidar deve associar o sonho e a ciência, o racional e a intuição, o emocional e os sentimentos, o real e o virtual, a imaginação e a criação, o espírito e o conhecimento, o visível e o invisível, o cotidiano e a subjetividade, o individual e o coletivo, e também, considerar particularidades e singularidades.

É preciso encontrar nos gestos e nas expressões das pessoas significados que determinem uma comunicação essencial, especial e simbólica para uma ação criativa concretizada no cuidado.

As enfermeiras, segundo afirmam Gauthier e Santos (1996), essas invasoras de intimidade, conhecem profundamente a "terra" onde trabalham com sua cultura, o ambiente dificil como é o Hospital, a Instituição de Saúde, a Empresa onde convivem cotidianamente com as relações de poder. Devem fluir nos "fluxos" e se enraizar na terra refletindo a própria fragilidade de reproduzir o que não gostam, mas que fazem com que elas vivam o seu "arco-iris" - cotidiano, caminhando entre clientes sadios e doentes, entre camas, calçadas, ruas, lares, morros. Neste paradigma é possível confrontar-se com diferenças sociais e individuais vivendo e trocando experiências.

O cuidar nos obriga a caminhar para encontrar uma indicação, uma direção a fim de mergulhar em nós mesmos; nos estimula a sonhar labirintos institucionais e a pensar em alternativas a partir do entendimento de que o ser humano é um ser desejante. Ele exige um aprofundamento, como afirmam os autores citados, na vida, no corpo e no inconsciente para encontrar a responsabilidade profissional, entendendo o cliente no centro das dificuldades, das responsabilidade e das decisões. 
Enfim, mudar o conceito de saúde para bem-estar é encontrar o lugar de invenção da um novo paradigma científico. Este é o lugar do cuidado com as pessoas, do respeito aos seus direitos e o reconhecimento de sua dignidade e humanidade. É dispor-se a sonhar, imaginar, criar e compartilhar com outros de belezas, misérias, forças, humildade, saberes e utopias.

\section{BIBLIOGRAFIA}

1. CLARKE, Artur - Um dia no século $X X I$, 2. ed. Rio de Janeiro: Nova Fronteira, 1989.

2. FIGUEIRÊDO, Nébia M. A. - A mais bela das Artes ... Tese (Concurso de Professor Titular de Enfermagem Fundamental). Rio de Janeiro, UNIRIO / EEAP, 1997.

3. GAUTHIER , Jacques; SANTOS, Iraci dos. - A Sócio Poética. Rio de Janeiro: Gráfica da UERJ, 1996.

4. GOUGES, Olimpe - Declaration des detroits de la femme. Paris, 1908. Reimpressão Auclert Humbertine, V. Girard and E. Briére.

5. HORTA, Wanda A. O processo de enfermagem. São Paulo: EDUSP, 1977.

6. LOURAU, René - Análise Institucional. 2. ed. Petrópolis: Vozes, 1996

7. LEININGER, Madaleine. Teoria do cuidado transcultural. ANAIS do I Seminário Brasileiro Teorias de Enfermagem. Florianópolis, UFSC, 20-24 maio, 1985.

8. MORIN, Edgard - Introduçâo ao pensamento complexo, Epistemologia e Sociedade. 2. ed. São Paulo: Instituto Piaget, 1990.

9. SANTOS, Iraci dos. A INSTITUIÇÃO DA CIENTIFICIDADE: Análise Institucional e Sócio-Poética das relações entre orientadores $e$ orientandos de pesquisa em enfermagem. ... Tese (Doutorado em Enfermagem). Rio de Janeiro. UFRJ, EEAN. 1997.

10. SOBRAL, Vera; FIGUEIRÊDO, Nébia - Os caminhos do trabalho feminino na Enfermagem - I EMBRACCE - Itapema-SC 1996. 